Chapter 10

\title{
Strategies for Neuroprotection in Glaucoma
}

\author{
Lizette Mowatt and Maynard Mc Intosh \\ Additional information is available at the end of the chapter \\ http://dx.doi.org/10.5772/53776
}

\section{Introduction}

Glaucoma has long been considered an irreversible progressive optic neuropathy with associated visual loss. Elevated intraocular pressure (IOP) was once considered the main modifiable risk for progression of glaucoma and has been the target for treatment. The pathogenesis of glaucoma was originally based on the mechanical and vascular dysregulation theory, however, this has evolved over the past decade. With the classification of low tension glaucoma, it is now recognized that the damage that occurs in the optic disc is not directly due to the elevated IOP and may be independent of this risk factor. Even though clinicians may aim for a target pressure, progression of optic disc cupping and visual field loss can still continue despite normal IOPs.

In contemplating a systematic approach to neuroprotection, the main areas to target include 1) neurotoxic agents such as nitric oxide and glutamate, 2) deprivation of internal neurotrophic factors 3) balancing self-repair with self-destruction in ocular nerve tissue and, 4) ocular blood flow and combating ischemia $[1,2,3]$. Focus in this chapter is dedicated to reviewing the mechanisms involved in the pathophysiology of neurodegeneration, target processes that offer neuroprotection, and the chemical and genetic interventions bearing potential for increasing retinal ganglion cell (RGC) survival. Glaucoma has cellular and molecular neurodegenerative pathways akin to those of other neurodegenerative disorders such as alzheimer's and parkinsons, which increases the accessibility to possible treatment options.

Gene therapy targets increased conventional and uveoscleral outflow, reduced aqueous production and prevention of wound healing in addition to neuroprotection. Interfering with the apoptosis cycle by gene therapy has also being considered by increasing neurotrophic factors [4]. Intravitreal injections of brain-derived neurotrophic factor (BDNF), a neurotrophin that improves neurogenesis and survival are being studied. Interestingly it has recently been noted in animal models that short periods of hyperglycemia may be protective to the retinal ganglion cells during periods of elevated intra ocular pressure [5]. 
Neuroprotection is the strategy to prevent retinal ganglion cell death. There have been several methods, many still experimental, aimed at reducing glutamate excitotoxicity, nitric oxide, free radical production and tumour necrosis factor (TNF) inhibition [1-4,6]. With the latest research, glaucoma, which was once thought to be an optic neuropathy, then a retinal disease, is now being considered a neurodegenerative disease, like alzheimer and parkinson [7].

This chapter will review the present pathophysiology theories of neurodegeneration in glaucoma and highlight the latest updates in neuroprotection strategies, mechanisms that block apoptosis and improving the survival and functionality of the retinal ganglion cell.

\section{Retinal ganglion cell death}

The neurodegeneration seen in glaucoma is as an end result of apoptosis (programmed cell death) of the retinal ganglion cell (RGC). When the retinal ganglion cell dies, there is a degenerative change along the axon with the resulting clinical findings including thinning of the retinal nerve fiber layer (objectively measured by Optical Coherence Tomography, Heidelberg Retinal Tomography or GDx) and increased optic disc cupping. Retinal ganglion cell apoptosis results in visual field loss and ultimately loss of vision in glaucoma. There are several etiologies for retinal ganglion cell (RGC) death which occurs with and without elevated intraocular pressures.

Retinal ganglion cell apoptosis is thought to be a result of several factors:

- increased intraocular pressure (IOP)

- glutamate excitotoxicity

- oxidative stress: free radical induced apoptosis (nitric oxide)

- neurotrophic factors deprivation

- glial cell activation

- abnormal immune response

- hypo perfusion

The glutamate and nitric oxide (NO) theories were the early proposed mechanisms for neurodegeneration. There is a proposed oxidative component which results in oxidative stress on the RGC due to increased IOP and hypoxia leading to apoptosis.

\section{Increased intraocular pressure}

Although neurodegeneration theories were considered because of progression despite normal IOPs, increased IOP does have a role in RGC death. Increased IOP can block axonal transport of the excitotoxic transmitter, glutamate, at the level of the lamina cribrosa, leading to depri- 
vation of neurotrophic factors. It is also theorized that a secondary release or decreased uptake of glutamate via the müller cells is another cause for retinal ganglion cell apoptosis. It has been noted that retinal ganglion cell death has been associated with elevated IOP with positive correlation with an increase in matrix metallopetidase- 9 (MMP-9) activity ( $<<0.001)$, tissue inhibitor of matrix metalloproteinase (TIMP-1) $(\mathrm{P}<0.05)$ and collagen $1(\mathrm{P}<0.01)$ [8].

With increased IOP, structural changes occur in the optic nerve head. There are several proposed theories for this effect. The mechanical bowing of the lamina cribrosa and loss of the axons may occur because of the hypo perfusion secondary to increased IOP. Optic nerve damage may be more prominent in hypotensive patients which may in part be due reduced perfusion and resulting oxidative stress from the induced hypoxia associated with reduced blood flow. In addition to this elevated IOP results in remodelling of the lamina cribrosa which may be a result of an increased synthesis of extracellular matrix ; matrix metalloproteases (MMP), collagen I and IV and elastin [9-11].

The upregulation of MMP may be due to either the vascular insufficiency with resulting ischemia or secondary to increased endothelin and TNF $\alpha$ production [12]. There is a significant correlation between MMP-9 activity and both RGC apoptosis $(\mathrm{P}<0.001)$ and loss of laminin (P $<0.01)[8,9]$. This change in the structure of the lamina cribosa may result in damage to the retinal ganglion cell axons as they traverse it [13]. Astrocyte activation can result from ischemia, increased hydrostatic pressure or damaged axons and this can propagate the process of structurally changing the lamina cribrosa, resulting in further damage to the transversing ganglion cell axons $[14,15]$.

\section{Glutamate}

Glutamate is an excitatory neurotransmitter that is continuously released by photoreceptors and OFF bipolar cells in the dark which results in the dark current. Light stimuli starts the process of phototransduction which leads to reduced glutamate concentration in the synaptic cleft. Glutamate transporters allow for the uptake of glutamate by müller cells which is converted by glutamine synthetase into glutamine which is then released by the glial cells. This glutamine is taken up by the neurons and hydrolysed by glutaminase to glutamate again. Glutamate allows the influx of calcium, resulting in high intracellular calcium levels which promote apoptosis. Glutamate in excess is neurotoxic, due to its induced excitotoxicity. The glutamate-glutamine cycle allows for natural homeostasis between the neurons and the glial cells (Figure 1).

Glutamate is released from degenerating cells or reduced uptake from müller's cells can increase the presence of glutamate. RGC may undergo apoptosis directly because of increased glutamate excitotoxicity. Müller cells can be injured by the excess glutamate which results in a secondary RGC death [16].

Glutamate ionotropic receptors are found on the post synaptic bipolar, horizontal, amacrine and ganglion cells. They are gating cation channels that are classified into 3 groups; N-methylD-aspartate (NMDA) receptors, $\alpha$-amino-3-hydroxy-5-methyl-4-isoxazolepropionic acid 
(AMPA) receptors and kainite receptors. In view of this glutamate receptor antagonists have been found to reduce the neurotoxic effect of increased glutamate levels.

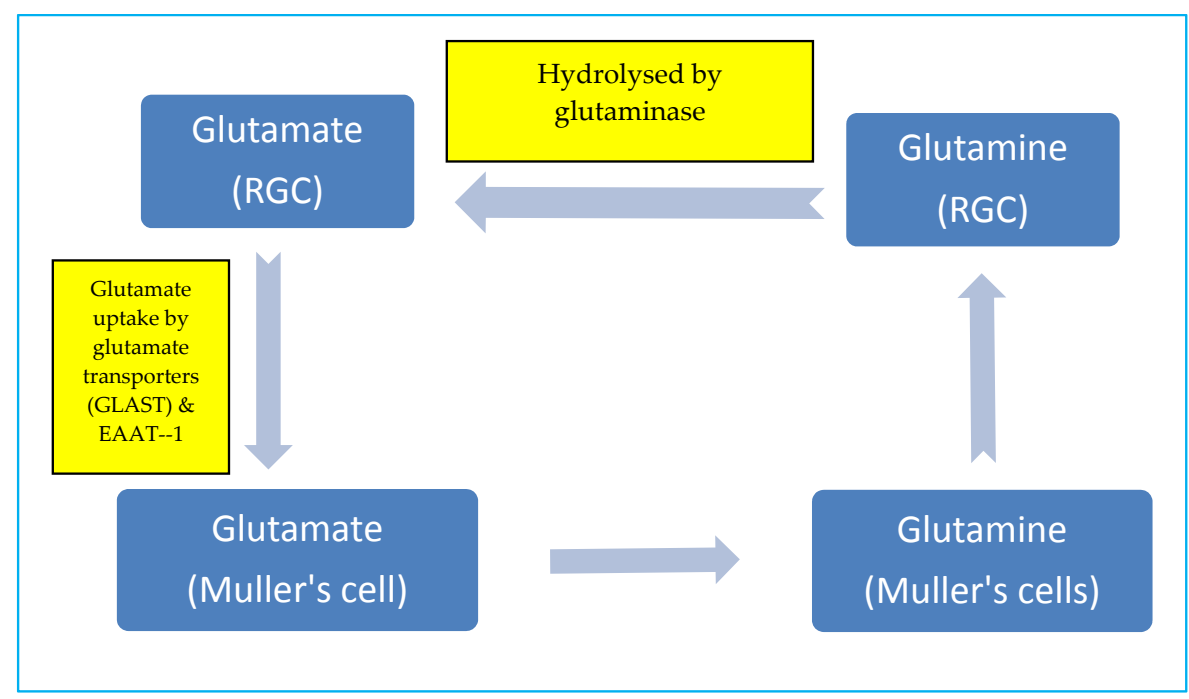

Figure 1. The glutamate-glutamine cycle (RGC= Retinal Ganglion cell, GLAST = Glutamate Aspartate transporter, EAAT-1 =Excitatory Amino Acid Transporter))

Increased glutamate has been noted in the vitreous of glaucoma patients [17]. However the glutamate transporters; glutamate aspartate transporter (GLAST) and excitatory amino acid transporter-1 (EAAT-1) are localized exclusively to müller's cells and glutamate transporter -1 (GLT-1) and excitatory amino acid transporter- 2 (EAAT-2) in the brain, decreased with increasing IOPs $[18,19,20]$ (Figure 1). Therefore, the increase IOP effect on the glutamate transporters can further aggravate glutamine neurotoxicity.

Mice deficient in excitatory amino acid carrier-1 (EAAC1) or GLAST had RGC apoptosis in the absence of elevated IOP. Neuronal EAAC1 does not play a direct role in glutamate transport but transports cysteine much more than GLAST. This is important for the glutathione synthesis. Lack of glutathione made the RGCs more susceptible to oxidative stress [21].

\section{Glutamate receptor antagonists}

The NMDA ionotropic glutamate receptor has been shown to have an important role in the mechanisms of certain CNS disorders, eg alzheimer's and parkinson's disease as seen in rat and human models [22,23,24]. Glutamate opens calcium and sodium channels after binding to the NMDA receptor, which results in a high intracellular influx of calcium which starts the cascade of apoptosis. Therefore, NMDA receptor blockers have been investigated for counteracting possible glutamate excitotoxicity. 


\subsection{Memantine}

Memantine, is a NMDA receptor blocker which is approved in the USA for dementia associated with alzheimer's disease. Although oral memantine clinically showed a protective effect on visual function and structural damage on macaque monkeys, it did not persist in long term treatment ( $>5$ months) on ERG findings $[25,26]$. It has been used at doses of $4 \mathrm{mg} / \mathrm{kg}$ po daily reaching concentrations of $0.3-1.8 \mathrm{uM}$ in the monkey vitreous $[25,26]$. The second phase III clinical trial showed that although the progression of disease was significantly lower in patients receiving the higher dose of memantine compared to patients receiving the low dose of memantine, there was no significant benefit compared to patients receiving placebo [27].

Latest animal studies have shown that using memantine in monkeys will result in an overall higher mean multifocal visual evoked potential (VEP) amplitudes than the non treated memantine monkeys when experimental glaucoma has been induced [28]. However it was not significant from baseline in the former. The use of the GDx in future studies will also allow more sensitive changes in retinal nerve fiber layer to be detected however, this may not directly be translated into functional damage, which in humans can be assesed with visual fields.

\subsection{Eliprodil}

This NMDA antagonist acts at the polyamine binding site of the NMDA receptor (NR2B subunit), blocking voltage dependent calcium channels. It has been shown to be neuroprotective in cultured neurons of brain and retina from excitotoxic and ischemia damage at doses of $1-10 \mathrm{mg} / \mathrm{kg}$ [29]. Eliprodil has shown reduction in the NMDA currents by $78 \%$ in a glutamate induced cytotoxicity model [30]. Although there has been promise of this drug in animal studies, clinical trials have not been undertaken for glaucoma in humans.

\subsection{Nitric oxide}

Nitric oxide (NO) is a neurotransmitter, vasodilator and neuromodulator and can be neurotoxic. Nitric oxide is found at the post junctional area of glutaminergic junctions (rods, bipolar, amacrine and ganglion cells) and acts as an intracellular mediator for glutamate. Excessive production of nitric oxide by astrocytes has been shown to play a rolein cell death in both theoptic nerve head and the RGC [2,3,6,31,32]. Reactive oxidative species (ROS) may play a role in neurodegeneration as a result of apoptosis (Figure 2).

\subsubsection{Oxidative stress}

Nitric oxide is produced by nitric oxide synthase (NOS-2). NOS has 3 isoforms inducible NO (iNO), endothelial $\mathrm{NO}(\mathrm{eNO})$ and neuronal $\mathrm{NO}(\mathrm{nNO})$. These oxidize L-arginine to L-citrulline, producing NO. Nitric oxide freely diffuses to adjacent neurons and combines with $\mathrm{O} 2-$ to form peroxynitrite anions (ONOO-) which is a potential toxin, setting into motion neuronal apoptosis. It can be induced by injury or cytokines, such as interleukin 1 beta, tumour necrosis factor alpha, resulting in high concentrations of nitric oxide [32,33]. Increased levels of NOS are seen in the optic nerve head of glaucoma patients [32]. Tumour necrosis factor (TNF) $\alpha$ is upregulated in the glaucomatous optic nerve head and induces NOS in the astrocytes [34]. 


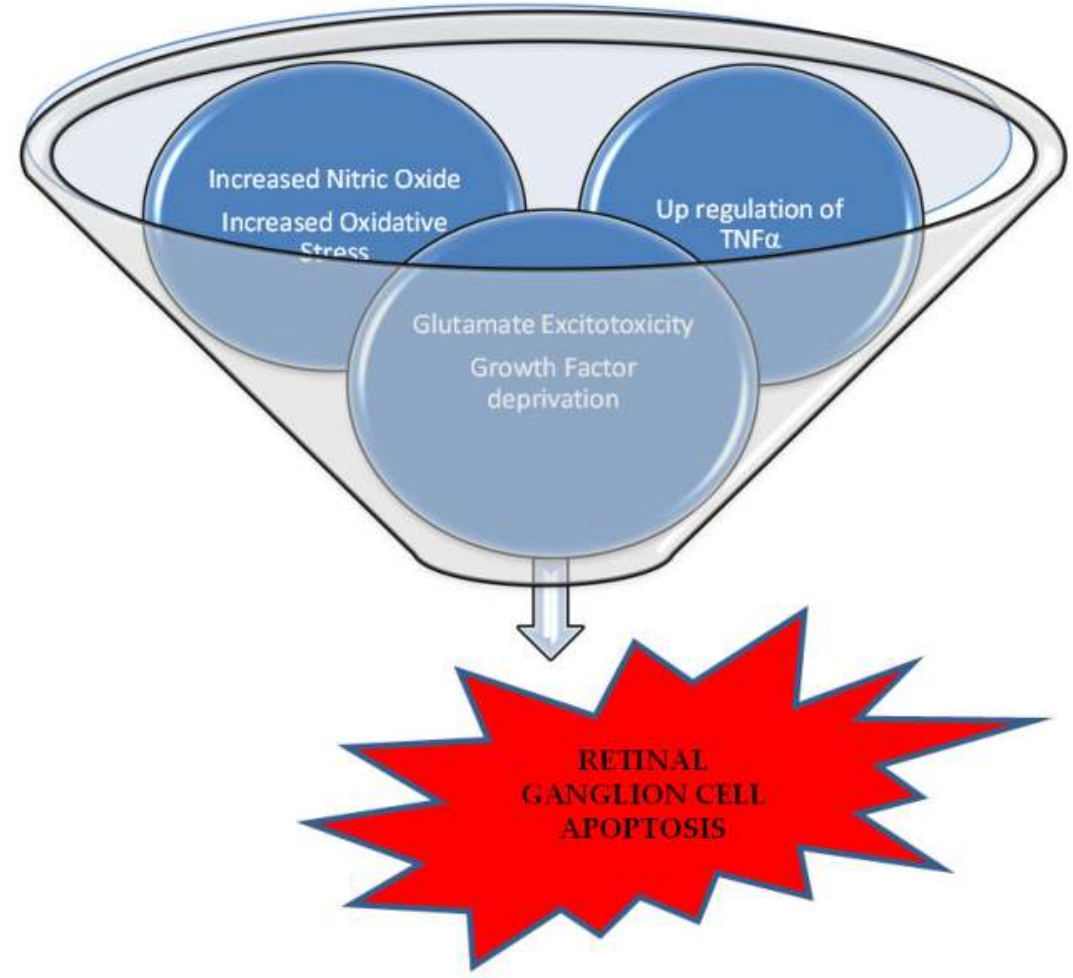

Figure 2. Multiple mechanisms for neurodegeneration which may be aggravated by vascular dysregulation, hypoxia and elevated IOP

nNO and iNO are expressed in reactive astrocytes. Increased NO reacts with a superoxide anion which can be toxic to the axons of the retinal ganglion cell. Motallebipour et al, showed a genetic association between iNO and primary open angle glaucoma (POAG) using genetic analysis and nuclear factor [35]. iNO is located in the astrocytes and microglial in the optic nerve head and expresses more activity with exposure to increased intraocular pressure and cytokines. This results in increased in NO production and the induction of the apoptotic cascade [36]. The NO oxide has its effect in both the astrocytes of the optic nerve head and the pericytes of the vasculature [32].

\subsubsection{Vascular modulation}

The endothelial NO synthase (eNOS) is expressed in the trabecular membrane and schlem's canal cells. eNOS produces nitric oxide which regulates the vascular tone causing smooth muscle relaxation and relaxation of the trabecular meshwork which improves aqueous humour outflow [37]. Elevation of the IOP increases the shear stress which activates eNOS which results in increase in the pressure dependent outflow. 


\subsubsection{The future}

Krauss 2011 and Impagnatiello 2011 have had success in lowering IOP in preclinical trials with a nitric oxide donating prostaglandin F2 agonist (BOL-303259-X) more than with latanoprost (prostaglandin F2 agonist) alone [38,39]. Fabrizi 2012, also had some success with combining a carbonic anhydrase inhibitor with a nitric oxide moiety, NCX250 in lowering IOP compared with the a carbonic anhydrase inhibitor alone [40].

\section{Alpha adrenergic receptor agonist}

$\alpha 2$ adrenergic agonists are a known group of anti glaucoma drugs that inhibit adenylate cyclase, reducing cAMP, thereby decreasing aqueous production. They also act by increasing uveoscleral outflow. $\alpha_{2 \mathrm{~A}}$ receptors can be found in non pigmented ciliary epithelium, $\alpha_{2 \mathrm{~B}}$ receptors on neuronal dendrites and $\alpha_{2 \mathrm{C}}$ receptors on photoreceptors cell bodies and inner segments [41]. $\alpha_{2}$ agonists have been shown to have secondary neuroprotective effects $[42,43,44]$.

\subsection{Brimonidine}

$\alpha 2$ adrenergic receptors can modulate the release of neurotransmitters such as glutamate [45]. NMDA receptors when stimulated results in an increase in intracellular $\mathrm{Ca} 2+$ and an inward current in the RGC. Brimonidine, an $\alpha 2$ agonist, can block the NMDA receptors which results in controlling the intracellular calcium, hereby allowing neuroprotection [23,46]. Brimonidine is also thought to up regulate brain derived neurotrophic factor (BDNF), activating anti apoptotic genes and the cell survival signaling pathway. It is also thought to modulate the $\mathrm{N}$ methyl-D-aspartate receptors [43,46-48].

Brimonidine is also known to upregulate not only BDNF, but prosurvival factors, such as anti apoptotic factors B-cell lymphoma -2 (Bcl-2) and B-cell lymphoma extra large (bcl-xl), basic fibroblastic growth factor (bFGF) and extracellular signal regulated kinases (ERKs). These actions assist in the prevention of neuronal death and promotes cell survival [49].

\section{Selective beta receptor blockade}

Beta blockers have a long history of use in reducing the IOP in glaucoma by reducing the production of aqueous humour. Levobetaxolol, timolol and metipranolol have been shown to have secondary neuroprotective effect by reducing sodium and calcium influx, which reduces the release of glutamate with levobetaxolol being more effective than timolol [50,51,52].

\subsection{Betaxolol}

Betaxolol has been shown to reduce the spontaneous firing rate by suppressing glutamategated current and in effect Na currents in the ganglion cells [52]. By doing this it also reversibly 
blocks the voltage gated calcium current. High intracellular calcium can be neurotoxic. Due to the $\mathrm{Ca} 2+$ channel blockage activity by the selective beta 1 beta blocker, betaxolol exerts a neuroprotective effect on the retinal ganglion cells. This effect can be seen at 2-50uM concentration [53]. Timolol is not effective even in higher concentrations (100uM) and clinically betaxolol is more efficacious in preserving visual fields in glaucoma patients compared to timolol [54]. It has been demonstrated in human cryopreserved retinal arterioles that intraluminal bextaolol caused a significant greater dilatation than timolol, this may be due to the selective nature of the beta blocker [55]

Betaxolol 0.5\% also upregulates the neurotrophic factor BDNF in retinal glia cells [56]. By its action on vascular smooth muscle relaxation this improves blood flow and reduces ischemia induced RGC apoptosis [52,57]. Retinal ganglion cells protection has been shown using rat experimental model and the preservation of the $a$ and $b$ waves in the electroretinogram in both ischemic-reperfusion and glutamate toxicity models $[56,57,58]$. This has also been seen in light response experiments on tiger salamander flat mounted retinas [53].

\section{Calcium channel blockade}

As high intracellular calcium can be neurotoxic reducing this effect can be neuroprotective to the cells. This effect can be seen in both beta blockers and alpha agonists [2] (Table 1).

\section{Prostaglandin analogs}

Prostaglandin analogs are known as a first line treatment for reducing the IOP. However, latanoprost and bimatoprost acid have shown a neuroprotective on hypoxic induced or glutamate exocitoxity on RGCs [58,59]. This was IOP independent and is not thought to be associated with normal mechanism to lower IOP [59]. Acting via prostaglandin F2 receptors, it has been suggested that latanoprost may have a COX 2 feedback inhibition resulting in neuroprotection [58]. It has also been shown that it inhibits inducible NOS [56]. Latanoprost may also be combined with the NO moiety as previously mentioned [38,39]. Further, it has been theorized that it may have an anti apoptotic effect through the inhibition of caspase-3 [58,60].

\section{Carbonic anhydrase inhibitors}

The hypotensive effect of carbonic anhydrase inhibitors is a result of reduction of aqueous humour production at the ciliary epithelium level. However in cultured retinal cells, RGC death is prevented by dorzolamide because of its anti-apoptotic pathway [60]. 


\begin{tabular}{|c|c|c|}
\hline NEUROPROTECTION & Substances studied & General Method of Action \\
\hline \multicolumn{3}{|l|}{ STRATEGIES } \\
\hline \multirow{2}{*}{$\begin{array}{l}\text { Glutamate Receptor Antagonists } \\
\text { - NMDA receptors }\end{array}$} & Memantine & Reduces glutamate excitotoxicity and \\
\hline & Eliprodil & neurotoxicity \\
\hline \multirow{4}{*}{$\begin{array}{l}\text { Nitric Oxide Synthase } \\
\text { Inhibitors }\end{array}$} & Combinations of nitric oxide donating & Reduce oxidative stress \\
\hline & prostaglandin F2 agonist and with a & \\
\hline & carbonic anhydrase inhibitor & \\
\hline & (experimental) & \\
\hline \multirow[t]{4}{*}{ Beta blockade } & Selective Beta Blockade (Betaxolol) & Reduces IOP \\
\hline & & Reduce glutamate production \\
\hline & & Upregulates BDNF \\
\hline & & Calcium channel blockade \\
\hline \multirow[t]{5}{*}{ Alpha adrenergic agonists } & Alpha 2 agonist (Brimonidine) & Reduces IOP \\
\hline & & Reduce glutamate production \\
\hline & & Upregulates BDNF \\
\hline & & Calcium channel blockade \\
\hline & & Increases anti apoptotic genes \\
\hline \multirow[t]{3}{*}{ Prostaglandin analogue } & Latanoprost acid & Reduces IOP \\
\hline & Bimatoprost acid & Inhibition of COX-2 activity \\
\hline & Tafluprost acid & Possible caspase 3 inhibition \\
\hline \multirow[t]{2}{*}{ Carbonic Anhydrase Inhibitor } & Dorzolamide & Reduces IOP \\
\hline & & Reduces apoptosis \\
\hline \multirow{2}{*}{$\begin{array}{l}\text { Neurotrophic factors } \\
\text { (BDNF and CNTF) }\end{array}$} & Brain Derived Neurotrophic Factor & suppress the intrinsic apoptosis whilst \\
\hline & Ciliary Derived Neurotrophic Factor & activating the survival signals \\
\hline \multirow{5}{*}{$\begin{array}{l}\text { Antioxidants: } \\
\text { Reactive Oxygen species } \\
\text { scavengers }\end{array}$} & Melatonin & activates anti oxidative enzymes \\
\hline & Vitamin E & Neutralizes free radicals. \\
\hline & Co Q10 cofactor & Oxidative stress can damage the \\
\hline & Manganese Tetrakis (in vitro) & trabecular meshwork, optic nerve head \\
\hline & & and retina. \\
\hline \multirow{4}{*}{$\begin{array}{l}\text { Immunmodulators } \\
\text { Anti Inflammatory agents } \\
\text { TNF- a Inhibitors }\end{array}$} & Cop-1(glatiramer acetate) & Immunization can modulate immune \\
\hline & Ethanrecept & function \\
\hline & Agmatine, an aminoguanidine & \\
\hline & Aspaminergic agent GLC756 & \\
\hline \multirow{2}{*}{$\begin{array}{l}\text { Gene Therapy } \\
\text { (Mitochondrial Augmentation) }\end{array}$} & Cycloheximide (CHX) & inducing neuroprotective genes \\
\hline & & including bcl-2 \\
\hline \multirow{4}{*}{$\begin{array}{l}\text { Apoptosis Inhibitors } \\
\text { Inhibition of cytochrome c } \\
\text { release } \\
\text { Caspase inhibitors }\end{array}$} & Deprenyl & Increase mitochondrial expression of \\
\hline & $\mathrm{BIRC4}$ & bcl-2 and bcl-x, suppresses bax. \\
\hline & & Improved neuronal survival \\
\hline & & \\
\hline \multirow[t]{2}{*}{ Hypo perfusion } & Gingko Bilboa & Improved blood flow \\
\hline & IOP lowering medications & \\
\hline
\end{tabular}

Table 1. Pharmacological neuroprotection strategies 


\section{Antioxidants}

Numerous studies have shown that mitochondrial metabolism results in the release of reactive oxidative species that cause damage to lipids, protein, resulting in cell death and neurodegeneration [61]. Hypoxia and ischemia are found to play an important role in the cascade of events leading to oxidative stress, and stimulating delta-opioid receptors (DOR) [62]. DOR has been proven to reduce the build-up of harmful free radicals, glutamate, and pro-inflammatory cytokines [62]. It has been shown that naloxone, an opioid blocker given intraperitoneally 6mg/ $\mathrm{kg}$ in rabbits can reduce the retinal thickness thinning caused by ischemia [63]. Morphine has been used to pharmacological pre condition rabbit retina and has been shown to reduce acute IOP induced damage [64]

\subsection{Coenzyme Q10 (Co Q10)}

Coenzyme Q10, either on its own or in combination with vitamin E (alpha -tocopherol ) have been shown to reduce intravitreal NMDA mediated damage in mice when adminsitered orally in $10 \mathrm{mg} / \mathrm{kg}$ dosage [65]. In addition to its effect against oxidative stress its positive effect on the mitochondria may assist in the energy levels within the neuron, protecting it from apoptosis [66]. The RGC requires energy produced from mitochondria to ensure the conduction of currents and normal function of the RGC. Agents that promote the ganglion cell mitochondrial energy production may be neuroprotective in glaucoma. Oral alpha-lipoic acid and nicotinamide have been suggested for further assessment for their neuroprotective effect on light induced neuronal apoptosis [67].

Ginkgo biloba may be useful for treating dementia associated with alzheimer and for vascular insufficiency. Although the mechanism of action remains unknown for its use in glaucoma, it is thought that it causes intracellular signaling and neutralizes reactive oxygen species $[13,68$, 69]. It has been shown to reduce the RGC axonal loss in mice compared to controls in a dose dependent manner after intragastral administration [68]. In one prospective randomized placebo controlled cross over trial, Ginkgo biloba extract was used 40mg tds orally for 4 weeks, which resulted in a statistically significant decrease in the corrected pattern standard deviation in visual fields of those patients [70].

Visual field defects have been noted to improve in patients with normal tension glaucoma after 4 weeks on gingko biloba and no ocular nor systemic adverse events occurred. Ginkgo biloba may exert multifactorial mechanisms which include increase ocular blood flow, anti oxidant activity, nitric oxide inhibition and improved cognitive function due to improved cerebral blood flow [70]. Manganese Tetrakis (4-benzoyl acid) porphyrin, a cell superoxide scavenger can prevent NO mediated motor neuron death in vitro [3]. Cycloheximide (CHX), a protein synthesis inhibitor has been used in doses of 50-500nM, to prevent neuronal death and protects against oxidative insults by inducing neuroprotective genes including bcl-2 [3]. 


\section{Neurotrophic factors}

\subsection{Brain derived neurotrophic factor}

Brain derived neurotropic factor is a neurotrophin derived from the brain (produced in the lateral geniculate body of primates) which moves in a retrograde fashion to bind TrkB receptors on RGC cell body and axon. Its retrograde transport is obstructed in acute and chronic glaucoma models, hence apoptosis occurs, as its neurotrophic support is important in RGC survival [13].

Eyes with chronic glaucoma exhibit loss of physiological neurotrophin levels particularly BDNF. Intravitreal injections of neurotrophins, eg BDNF has shown a reduction in apoptotic RGC death in adult rat models [71]. A recent study considered the cost effective use of serum BDNF as a biomarker for early POAG as its levels were significantly decreased in glaucoma patients compared with controls [72].

\subsubsection{Role in neuroprotection}

BDNF acts through Trk B receptors; phosphorylating kinase enzyme, activating phosphoinositol 3-kinase thereby inhibiting the activation of capsase 3, an important link in the apoptosis pathway (Figure 3). Experimentally BDNF has shown little effect on RGC survival in a single dose, but repeated intravitreal injections as well as virally mediated over expression has been shown to slow RGC loss [4]. It has been used at doses of $25-100 \mathrm{ug} / \mathrm{kg}$ in clinical trials [73]

\subsection{Ciliary derived neurotrophic factor}

Ciliary derived neurotrophic factor (CNTF) is a secretor- protein expressed in cells of all retinal layers and the optic nerve head. The protein shows increased expression in retinal and optic nerve injuries, and is reduced in the presence of increased IOP [4]. The protein demonstrates neuroprotection in virally-mediated overexpression after intravitreal injection. In one study by Pease et al, CNTF showed a 15\% less axonal death in experimental induced glaucoma, which was statistically significant over combined CNTF- BDNF and BDNF alone [74]. Intraocular delivery of neurotrophins, BDNF and CNTF, intravitreal or by viral transfer may be a potential future development for neuroprotection [4].

\section{Immune modulation}

\subsection{Anti-inflammatory agents}

There is an inflammatory component to the neuronal retinal degeneration in glaucoma [75-78]. Studies have proved an age related susceptibility of glaucoma victims to progressive nerve damage and RGC loss even with single digit IOP [4]. Researchers have also established elements of the complement pathway such as $\mathrm{C} 1 \mathrm{q}$, as markers for astrocyte destruction that 
may result in RGC apoptosis [78]. Thus, the future of glaucoma therapy lies in employing additional modalities based on proven mechanisms of RGC loss.

\section{Apoptotic Pathway}

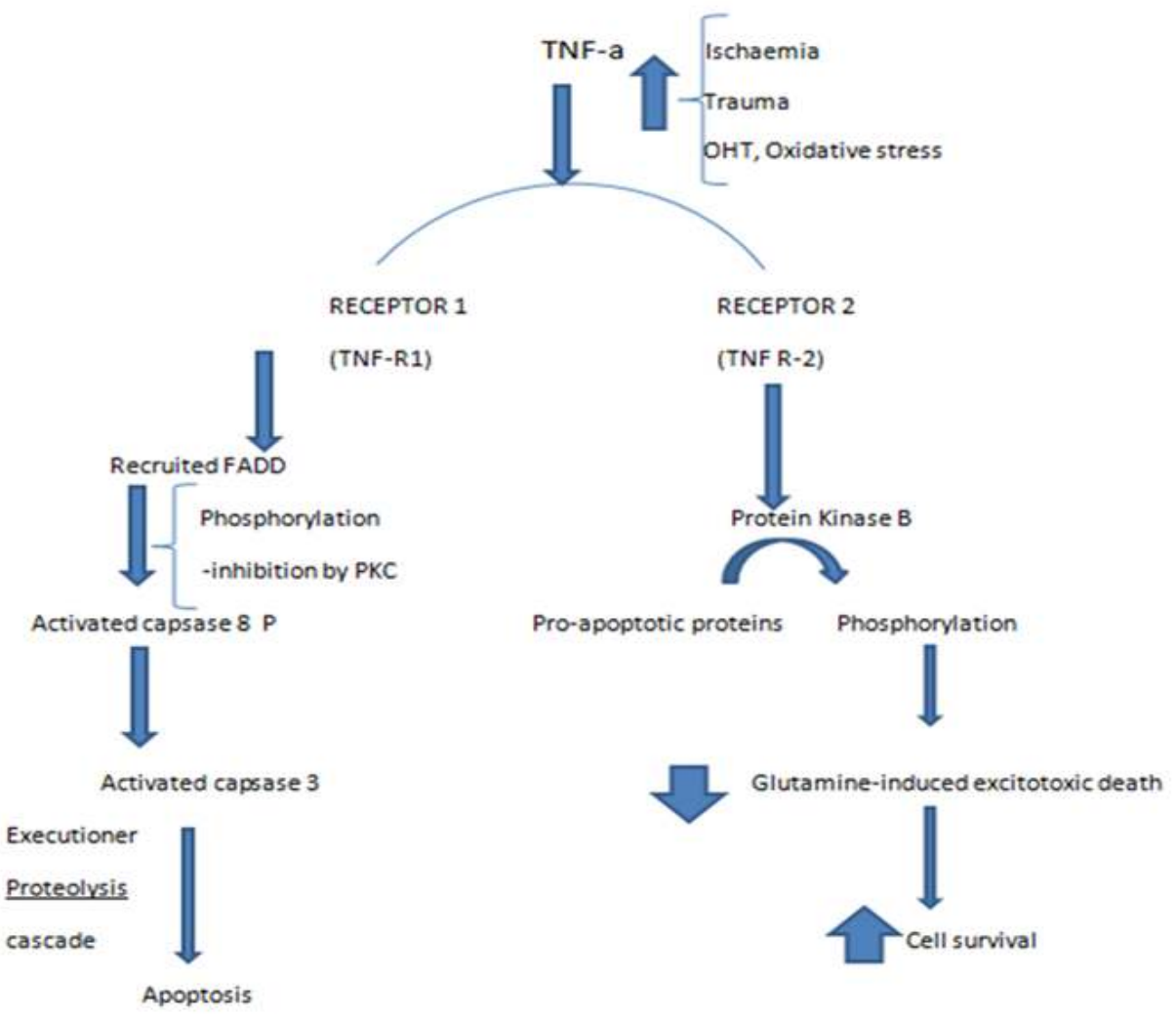

Figure 3. Apoptosis Pathway for Retinal Ganglion Cells

\subsection{Tumour Necrosis Factor $\alpha$ (TNF $\alpha)$}

Progression of optic nerve axonal degeneration and retinal ganglion cell (RGC) apoptosis, have been shown to be responsible for progressive visual field loss in glaucoma, with or without ocular hypertension. One mechanism has been linked to tumor necrosis factor (TNF- $\alpha$ ) in tissue around the optic nerve head demonstrated during immunostaining of mouse specimen [77]. This protein is a pro-inflammatory cytokine produced in response to trauma and inflammation and can start the apoptotic cascade [77] (Figure 3). TNF- $\alpha$, secreted by damaged glials cells and through the binding of TNF receptor-1 (TNF-R1) starts the apoptotic process 
stimulating caspase ultimately leading to RGC death [79] (Figure 1). However the binding of the TNF-R1 receptor also triggers via heat shock proteins and activation of transcription factor NF-KB, a cell survival pathway. TNF- $\alpha$ levels if at best optimized (kept low) create a homeostasis that facilitates a balance between neuroprotection and neurodegeneration $[75,79]$.

TNF- $\alpha$ is one of a 19-member family of ligands that exert their inflammatory activities through 29 receptors, triggering a cascade of inflammatory responses. TNF- $\alpha$ has been found to be upregulated in neurodegenerative diseases such as parkinson's and alzheimer's disease. In studies on the brain tissue of Alzheimer's patients, TNF- $\alpha$, a mediator of chronic inflammation, has been detected in increased levels [76].

TNF- $\alpha$ in some studies was found in high concentration after laser-induced OHT, along with increased macrophage/microglia near the optic nerve head [77]. The levels of TNF $\alpha$ surpassed those in other inflammatory processes not involving ocular hypertension, validating the protein as a likely mediator of the RGC death, and hence a target for gene therapy. The increase in microglia population in the vitreous surface around the optic nerve head also alludes to an inflammation theory of glaucomatous optic nerve and RGC damage [77]. Research in alzheimer's has established TNF- $\alpha$ as a mediator of chronic inflammation with detection of increased levels in the brain of victims of this neurodegenerative disorder [76]. Serum amyloid A, is another acute-phase inflammatory marker discovered in the retina and trabecular meshwork of glaucoma eyes [78]. An understanding of the molecular processes in parallel disorders will influence the outlook on the future of glaucoma management.

Agarwal et al 2012, reported on extensive research evidence in support of the role of TNF- $\alpha$ in glaucomatous optic nerve degeneration and RGC apoptosis [75]. Research involved eyes with POAG, NTG and exfoliative glaucoma, with cataract eyes as controls [75]. Results showed marked elevation in TNF- $\alpha$ in aqueous samples of all glaucoma groups compared with controls. In addition, optic nerve degeneration and RGC loss were demonstrated in eyes subject to intravitreal injection of TNF- $\alpha$.

\subsubsection{How does TNF- $\alpha$ work?}

Under normal conditions there is greater expression of TNF-R1 over TNF- $\alpha$. Stress factors such as trauma, ischaemia, and elevated hydrostatic pressure result in an increase in expression of TNF-R1 and TNF- $\alpha$. These have been shown to have several roles including pro-apoptotic and neuroprotective properties depending on the environment in which they are expressed [Figure 3]. Experimental evidence using mouse eyes have shown that in the absence of normal glial cells, the apoptotic effect dominates. Microglial cells are thought to provide survival signals necessary for the neuroprotective effect of TNF- $\alpha$. Insults such as ischemia, oxidative stress and optic nerve injury increases the expression of cell death signals and reduces the expression of the cell survival signals, thereby potentiating the harmful effects of TNF- $\alpha$ [61].

In contrast, normally functioning glial cells support the neuroprotective effects of TNF- $\alpha$ and TNF-R1. The ischaemic and hydrostatic stress in glaucoma activate microglial activity causing an inflammatory response. Activated glial cells produce TNF- $\alpha$ along with harmful compounds like NO and endothelin 1 (ET-1). In excessive microglial activation, up regulation of 
TNF $\alpha$ - causes RGC apoptosis in the absence of normal glial support. If there is significant microglial insult early in the event, TNF $\alpha$ - continues to exert apoptosis even after the stimulus is removed, as has been shown in in-vivo studies with mice, where progression of RGC death was seen on immunostaining even after normal IOPs were reached [75].

\subsection{Agmatine, an aminoguanidine}

Current research targets TNF- $\alpha$ for neuroprotection by reducing RGC loss (Figure 3). Such agents need to have high selectivity and specificity for excessive TNF- $\alpha$ and TNF-1 expression while preserving local immunity. Agents such as Agmatine, an aminoguanidine, have been shown to protect RGCs against the apoptotic effects of TNF- $\alpha$, but the effects on other receptors and pathways are yet to be established $[44,45,75]$. Agmatine has been used at a concentration of $60 \mathrm{mg}$ daily in rat ocular hypertension model [31]. 10(-3) M agmatine solution 4 times a day has shown a high affinity for alpha 2 receptors on the ciliary body, where it exerts its IOP lowering effect which has been seen in the rat model [80]. Amnioguanidine also targets inducible nitric oxide synthase (iNOS) inhibitors [31,73].

\subsection{Ethanrecept, the future in neuroprotection}

Work done by Roh et. al (2012) demonstrated the ability of ethanrecept, a recombinant chimeric protein, to act as a TNF $\alpha$ inhibitor to reduce RGC loss in the wake of elevated TNF $\alpha$ [77]. This decoy protein selectively binds TNF $\alpha$, sparing the RGC damage from this and other inflammatory agents such as microglia [77]. Ethanrecept is used in the treatment of juvenile idiopathic arthritis, rheumatoid arthritis, ankylosing spondylitis, and psoriatic arthritis, and has shown no IOP-lowering capabilities. The drug however shows promise as a neuroprotective agent for intravitreal use in the future.

\subsection{Copolymer -1 (Cop-1), - A possible vaccination for neuroprotection?}

The inflammatory process in neurodegenerative diseases such as alzheimer's and glaucoma has been found to be associated with pro-inflammatory activities mediated in part by $\mathrm{T}$ cell activity. Cop-1, a synthetic peptide polymer known to suppress autoimmune encephalomyelitis, modulates this $\mathrm{T}$ cell reaction by producing a Th2 anti-inflammatory phenotype with attenuation of normal inflammatory response in neurodegenerative diseases as well as increased neuroprotection [13, 81,82]. Cop-1, glatiramer acetate has been FDA approved in the treatment of multiple sclerosis, a demyelinating disease.

It had been noted experimentally that an eye that had recent glutamate injections had resulting large numbers of lymphocytes present, hence it was theorized that glutamate toxicity induces a T cell lymphocyte reaction [81]. Therefore, by immunizing against this with the correct antigen, theoretically could reduce the damage induced by the glutamate. Cop- 1 immunization has shown some protection against glutamate toxicity and elevated IOP in mice retinal ganglion cells $[81,82,83]$. So $\mathrm{T}$ cell mediated immunoprotection may be a future option for glaucoma, however, much research is still to be done. 


\subsubsection{Opioids}

Opioid receptor activation has been shown to reduce the ischemic damage to the retina as demonstrated by ERG [84]. Opioid receptor stimulation and the facilitation of the actions of endogenous opioids show promise in neuroprotection of RGCs in glaucoma $[84,85]$. In the mice model, glaucoma was induced by raising the IOP above the systolic blood pressure (155-160mmHg) for 45 minutes to induce ischemic retinal injury [84]. The opioid antagonist naloxone $(3 \mathrm{mg} / \mathrm{kg})$ was given to mice intraperitoneally 24 hours before the ischemic event. Another study group of mice had morphine $(0.01-10 \mathrm{mg} / \mathrm{kg}$ given intraperitoneallly 24 hours before the ischemic injury. 7 days after the injury the retina of both groups were assessed by the ERG. The mice that has morphine had greater preservation of their ERG a and $b$ wave amplitudes 7 days after the ischemic event. Further the protective effect of morphine on preservation of ERG amplitudes was dose related with the ED50 of $0.18 \mathrm{mg} / \mathrm{kg}$ [84]. However, these strategies have not yet been tested in humans or undergone randomized controlled trials.

\section{Stem cells}

Much research is still yet to be done on stem cells and neuroprotection. Stem cells can supply neurotrophins and modulate matrix metalloproteinases after an injury which can be neuroprotective and limit neuronal damage [86]. However in a pre-clinical model of glaucoma, intravitreal stem cell injections have been shown to enhance the survival of the RGC [23].

\section{Gene therapy}

With emerging evidence for the molecular basis in glaucoma- pathophysiology, the disease may be interrupted by targeting key sites once the genetic expression is known. Studies of micro-RNA such as miRNA-125b has led to the understanding of the key sites for targeted down-regulation of messenger RNA which is thought to add to the oxidative stress induction of inflammation and astrogliosis in alzheimer's disease [78]. Alzheimer's disease, parkinson and glaucoma are thought to have a similar neurodegenerative basis (molecular and cellular pathways for neuronal cell loss) [78]. Hence gene therapy for glaucoma and other neurodegenerative disorders may be where medical management is headed. Target sites include uveoscleral outflow site, surgical (trabeculectomy) site, ciliary apparatus, retina and optic nerve head (neuroprotection) [4].

Gene therapy would be helpful in preventing neurodegeneration using anti apoptotic genes, bcl-2 and bcl-x [2]. Another mechanism is blocking the apoptotic pathway with deprenyl (monamine oxidase inhibitor). It is proposed that it stabilizes the mitochondrial membrane potential, preventing the release of cytochrome $\mathrm{c}$ which can activate capsases (Figure 1) [2, 87].

Targeting antioxidant genes is a promising strategy for future management of glaucomatous neurodegeneration. Researchers used cloned extracellular superoxide dismutase (ECSOD) or 
catalase (CAT), carried on recombinant adeno associated virus intravitreally in mice. The mice were euthanized and optic nerve volume, myelin fibre area, axonal cell loss and RGC loss evaluated Inital response showed a 15 fold increase in ECSOD and 3.3-fold in CAT [88]. After six months the authors reported 29\% reduction in RGC loss, $36 \%$ in ON demyelination, and reduction in axonal loss by $44 \%$ all compared to control eyes, indicating that antioxidant gene therapy will prove an invaluable adjunct to current glaucoma therapy.

\subsection{Administering gene therapy}

Administration of gene therapy must ideally be safe, repeatable, have low immunogenicity, and carry low infectious and mutagenic potential, modification of Koch's postulates [4]. Because viral vectors have the ability to maintain stable DNA within the target nucleus, they are preferred over non-viral vectors.

\subsubsection{Viral vectors}

Adenoviral vectors $(A d)$, non-enveloped replication-deficient recombinant viruses were the first to be used in gene therapy research $[4,89]$. They show high level of tropism for post mitotic and highly specialized cells, and have been known to reproduce TM cells with high accuracy. They have application in Muller cell and RPE cell replication as well. Studies have been done with Adenovirus (Ad) mediated intravitreal delivery of BDNF. However, repeated injections have been found to cause severe inflammation in experimental models $[2,90]$

Adeno-associated Viruses ( $A A V$ ). This is an integrating vector known to show efficient delivery to target tissues. AAVs do not carry viral genes, therefore they have no unwanted pathogenicity, immunogenicity, nor significant inflammation upon sub retinal application [2]. In the last 4 years the use of AAV vector in the delivery of gene therapy has met some success in human trials, but the effect is limited to RGC survival. Though the vectors may target trabecular meshwork cells, they are not very active there [89].

Herpes Simplex Virus (HSV). This virus has shown promise in glaucoma research and therapy as it is able to transduce trabecular meshwork, ciliary body epithelial, and retinal ganglion cells. The injected derivative however has been found to carry risks of inflammation, toxicity, and limited duration of gene expression [4].

Lentiviral vectors. These single strand RNA viruses can incorporate trabecular meshwork and RGC DNA by reverse transcription, with both neuroprotective and IOP lowering potential. Combining several enzymes such as cyclooxygenase and prostaglandin pathway enzymes increases their IOP-lowering properties. [90]

\subsubsection{Non-viral vectors}

Naked DNA Injection. Work done with naked DNA as plasmid vectors expressing chloramphenicol acetyl transferase has shown promise in the possible control of wound healing after trabeculectomy. The plasmid injected in the bleb or under collagen shield has resulted in a 30 fold increase in the activity of the enzyme. [4]. 
The use of short 21 siRNA by intracameral and intravitreal injection to silence the unwanted expression of glaucoma genes particularly in the trabecular meshwork is being studied. The effects are so far temporary, and such siRNAs need the assistance of developed nanoparticles, such as magnetic nanoparticles, to enter target cells [89]. Chemical approach include the use of cationic lipids (liposomes) used in vitro, and shows promise for in vivo application via intracameral route with the target tissue being trabecular meshwork [4].

\section{Conclusion}

The cause of glaucoma and ultimately retinal ganglion cell death is multifactorial. At present there is no cure for glaucoma and the mainstay of treatment medically and surgically is to control the IOP. However, this conventional approach of lowering IOP is merely a secondary or indirect approach to the real problem. Current studies show that glaucoma is a neurodegenerative disease with neuroprotection and possibly neuroregeneration and neuro enhancement as the future treatment modality. Modified Koch's postulates have been applied in the experimental neuroprotective research. Ultimately the retinal ganglion cell death whether primary or secondary (bystander result) must be stopped and the neurons preserved. The clinical application of most of these experimental neuroprotective strategies still has yet to pass through randomized controlled clinical trials before they can be accepted. The future holds much promise as to possible effective neuroprotective strategies, however, much research is still yet to be done.

\section{Author details}

Lizette Mowatt ${ }^{1,2^{*}}$ and Maynard Mc Intosh ${ }^{3}$

*Address all correspondence to: lizettemowatt@yahoo.com

1 Faculty of Medical Sciences, University of the West Indies, Jamaica

2 University Hospital of the West Indies, Mona, Jamaica

3 St Joseph Hospital, Kingston, Jamaica

\section{References}

[1] Chang EE, Goldberg JL. Glaucoma 2.0: neuroprotection, neuroregeneration, neuroenhancement. Ophthalmology. 2012 ;119:979-86. 
[2] Kwon YH, Mansberger SL, Cioffi GA. Ganglion Cell Death in Glaucoma: Mechanisms and Neuroprotective Strategies. Ophthalmology Clinics of North America. 2000;13:465-479

[3] Naskar R, Dreyer EB New Horizons in Neuroprotection. Surv Ophthalmol 2001. 45 (Suppl 3):S250-S255

[4] Liu X, Rasmussen CA, Gabelt BT, Brandt CR, Kaufman PL. Gene therapy targeting glaucoma: where are we? Surv Ophthalmol. 2009 ;54:472-86

[5] Ebneter A, Chidlow G, Wood JP, Casson RJ. Protection of retinal ganglion cells and the optic nerve during short-term hyperglycemia in experimental glaucoma.Arch Ophthalmol. 2011;129:1337-44

[6] Halpern DL, Grosskreutz CL. Glaucomatous optic neuropathy: mechanisms of disease.Ophthalmol Clin North Am. 2002 ;15:61-8

[7] Bayer AU, Keller ON, Ferrari F, Maag KP. Association of glaucoma with neurodegenerative diseases with apoptotic cell death: Alzheimer's disease and Parkinson's disease.Am J Ophthalmol. 2002 Jan;133:135-7

[8] Guo L, Moss SE, Alexander RA, Ali RR, Fitzke FW, Cordeiro MF. Retinal ganglion cell apoptosis in glaucoma is related to intraocular pressure and IOP-induced effects on extracellular matrix. Invest Ophthalmol Vis Sci. 2005 ;46:175-82

[9] Yan X, Tezel G, Wax MB, et al. Matrix metalloprotineinases and tumour necrosis factor alpha in glaucomatous optic nerve head. Arch Ophthalmol 2000;118:666-73

[10] Agapova OA, Kaufman PL, Lucarelli MJ, et al. Differential expression of matric metalloproteinases in monkey eyes with experimental glaucoma or optic nerve transection. Brain Res 2003;967:132-43

[11] Hermandez MR, Pena JD, The optic nerve head in glaucomatous optic neuropathy. Arch Ophthalmol 1997;115:389-95

[12] Golubnitschaja O, Yeghiazaryan K, Liu R, Mönkemann H, Leppert D, Schild H, Haefliger IO, Flammer J. Increased expression of matrix metalloproteinases in mononuclear blood cells of normal-tension glaucoma patients. J Glaucoma. 2004;13:66-72

[13] Kuehn MH, Fingert JH, Kwon YH, Retinal Ganglion Cell Death in Glaucoma: Mechanisms and Neuroprotective Strategies. Ophthalmol Clin N Am 2005 ;18:383-395

[14] Ridet JL, Malhotra SK, Privat A, et al. Reactive Astrocyes; cellular and molecular cues to biological function. Trends Neurosci 1997:20:570-7

[15] Hernandez MR, Pena JD, Selvidge JA, et al. Hydrostatic pressure stimulates synthesis of elastin in cultured optic nerve head astrocytes. Glia 2000;32:122-36

[16] Ullian EM, Barkis WB, Chen S, et al. Invulnerability of retinal ganglion cells to NMDA excitotoxicity. Mol Cell Neurosci 2004;26:544-57 
[17] Dreyer E, Zurakowski D, Schumer R, et al. Elevated glutamate levels in the vitreous body of humans and monkeys with glaucoma. Arch Ophthalmol. 1996;114:299-305

[18] Martin KRG, Levkovitch-Verbin H, Valenta D,Baumrind L, Pease ME, Quigley ,HA. Retinal Glutamate transporter changes in Experimental Gluacoma and after Optic Nerve Transection in the Rat. Invest Ophthalmol Vis Sci. 2002;43:2236-2243

[19] Vorwerk CK, Naskar R, Schuettauf F, et al. Depression of retinal glutamate transporter function leads to elevated intravitreal glutamate levels and ganglion cell death. Invest Ophthalmol Vis Sci. 2000;41:3615-3621

[20] Naskar R, Vorwek CK, Dreyer EB. Concurrent downregulation of a glutamate transporter and receptor in glaucoma. Invet Ophthalmol Vis Sci. 2000. 41:1940-4

[21] Harada T, Harada C, Nakamura Kazuaki, Quah HA, Okumura A,Nakamekata K, Saeki T, Aihara M, Yoshida H, et al.The potential role of glutamate transporers in the pathogenesis of normal tension glaucoma. J Clin Invest. 2007;117:1763-1770

[22] Sonkusare SK, Kaul CL, Ramarao P. Dementia of Alzheimer's disease and other neurodegenerative disorders - memantine, a new hope. Pharmacol Res. 2005;51:1-17

[23] Johnson KA, Conn PJ, Niswender CM. Glutamate receptors as therapeutic targets for Parkinson's disease. CNS Neurol Disord Drug Targets. 2009;8:475-91.

[24] Nandhu MS, Paul J, Kuruvila KP, Abraham PM, Antony S, Paulose CS. Glutamate and NMDA receptors activation leads to cerebellar dysfunction and impaired motor coordination in unilateral 6-hydroxydopamine lesioned Parkinson's rat: functional recovery with bone marrow cells, serotonin and GABA. Mol Cell Biochem. 2011 l; 353:47-57

[25] Hare WA, WoldeMussie E, Lai RK, Ton H, Ruiz G, Chun T, Wheeler L. Efficacy and safety of memantine treatment for reduction of changes associated with experimental glaucoma in monkey, I: Functional measures. Invest Ophthalmol Vis Sci. 2004;45:2625-39. Erratum in: Invest Ophthalmol Vis Sci. 2004;45:2878.

[26] Hare WA, WoldeMussie E, Weinreb RN, Ton H, Ruiz G, Wijono M, Feldmann B, Zangwill L, Wheeler L. Efficacy and safety of memantine treatment for reduction of changes associated with experimental glaucoma in monkey, II: Structural measures.Invest Ophthalmol Vis Sci. 2004;45:2640-51

[27] Wheeler L, The future of neuroprotection in glaucoma therapeutics. Acta Ophthalmologica, 2008;86: 0. doi: 10.1111/j.1755-3768.2008.6446.x-i1

[28] Gabelt BT, Rasmussen CA, Tektas OY, Kim CB, Peterson JC, Nork TM, Hoeve JN, Lütjen-Drecoll E, Kaufman PL Structure/function studies and the effects of memantine in monkeys with experimental glaucoma. Invest Ophthalmol Vis Sci. 2012 ; 53:2368-76 
[29] Kapin M, DOshi R, Scatton B, DeSantis LM, Chandler ML. Neuroprotective Effects of Eliprodil in Retina Excitotoxicity and Ischemia. Invest Ophthalmol Vis Sci 1999;40:1177-1182

[30] Pang IH, Wexler EM, Nawy S, DeSantis L, Kapin MA.Protection by eliprodil against excitotoxicity in cultured rat retinal ganglion cells. Invest Ophthalmol Vis Sci. 1999;40:1170-6.

[31] Neufeld AH, Sawada A, Becker B.Inhibition of nitric-oxide synthase 2 by aminoguanidine provides neuroprotection of retinal ganglion cells in a rat model of chronic glaucoma. Proc Natl Acad Sci U S A. 1999;96:9944-8

[32] Neufeld AH, Hermandez MR, Gonzalez M: Nitric Oxide synthase in the human glaucomatous optic nerve head. Arch Ophthalmol 1997;115:497-503

[33] Nathan C, Xie QW. Nitric oxide synthases: roles, tolls and controls. Cell 1994;78:915-8

[34] Yuan L, Neufeld AH. Tumor necrosis factor-alpha: a potentially neurodestructive cytokine produced by glia in the human glaucomatous optic nerve head. Glia. 2000; 32:42-50

[35] Motallebipour M, Rada-Iglesias A, Jansson M, Wadelius C. The promoter of inducible nitric oxide synthase implicated in glaucoma based on genetic analysis and nuclear factor binding. Molecular Vision 2005; 11:950-7

[36] Agarwal R, Gupta SK, Agarwal P, Saxena R, Agrawal SS. Current concepts in the pathophysiology of glaucoma. Indian J Ophthalmol. 2009 ;57:257-66.

[37] Ellis DZ, Sharif NA, Dismuke WM. Endogenous regulation of human Schlemm's canal cell volume by nitric oxide signaling. Invest Ophthalmol Vis Sci. 2010;51:58175824

[38] Krauss AH, Impagnatiello F, Toris CB, Gale DC, Prasanna G, Borghi V, Chiroli V, Chong WK, Carreiro ST, Ongini E.Ocular hypotensive activity of BOL-303259-X, a nitric oxide donating prostaglandin F2 $\alpha$ agonist, in preclinical models. Exp Eye Res. $2011 ; 93: 250-5$

[39] Impagnatiello F, Borghi V, Gale DC, et al. A dual acting compound with latanoprost amide and nitric oxide releasing properties, shows ocular hypotensive effects in rabbits and dogs. Exp Eye Res.2011;03:243-249

[40] Fabrizi F, Mincione F, Somma T, Scozzafava G, Galassi F, Masini E, Impagnatiello F, Supuran CT.A new approach to antiglaucoma drugs: carbonic anhydrase inhibitors with or without NO donating moieties. Mechanism of action and preliminary pharmacology. J Enzyme Inhib Med Chem. 2012 ;27:138-47

[41] Woldemussie E, Wijono M, Pow D. Localization of alpha 2 receptors in ocular tissue. Vis Neurosci. 2007;24:745-756. 
[42] Yoles E, Wheeler LA, Schwartz M. Alpha 2 adrenoreceptor agonists are neuroprotective in a rat model of optic nerve degeneration. Invest Ophthalmol Vis. Sci. 1999:40;65-73

[43] Wheeler LA, Lai R, WoldeMussie E. From the lab to the clinic: activation of an alpha-2 agonist pathway is neuroprotective in models of retinal and optic nerve injury. Eur J Ophthalmol. 1999;9:S17-S21.

[44] Pinar-Sueiro S, Urcola H, Rivas MA, Vecino E. Prevention of retinal ganglion cell swelling by systemic brimonidine in a rat experimental glaucoma model. Clin Experiment. Ophthalmol 2011:39;799-807

[45] Pan YZ, Li DP, Pan HL. Inhibition of glutamatergic synaptic input to spinal lamina II(o) neurons by presynaptic alpha(2)-adrenergic receptors. J Neurophysiol. 2002;87:1938-1947

[46] Dong CJ, Guo Y, Agey P, Wheeler L, and Hare WA. Alpha2 Adrenergic Modulation of NMDA Receptor Function as a Major Mechanism of RGC Protection in Experimental Glaucoma and Retinal Excitotoxicity. Invest. Ophthalmol. Vis. Sci. October 2008; 49: 4515-4522

[47] Gao H, Qiao X, Cantor LB, et al. Up-regulation of brain-derived neurotrophic factor expression by brimonidine in rat retinal ganglion cells. Arch Ophthalmol. 2002;120:797-803

[48] Lai RK, Chun T, Hasson D, et al. Alpha-2 adrenoceptor agonist protects retinal function after acute retinal ischemic injury in the rat. Vis Neurosci. 2002;19:175-185

[49] Tatton W, Chen D, Chalmers-Redman R, Wheeler L, Nixon R, Tatton N. Hypothesis for a common basis for neuroprotection in glaucoma and Alzheimer's disease:anti apoptosis by alpha 2 adrenergic receptor activation. Surv Ophthalmol 2003; 48 (Suppl 1), S25-37

[50] Osborne NN, Cazeviville C, Carvalho AL, Larsen AK, DeSantis L. In vivo and in vitro experiments show that betaxolol is a retinal neuroprotective agent. Brain Res. 1997:751;113-123

[51] Wood JP, Schmidt KG, Melena J, Chidlow G, Allmier H, Osborne NN. The beta adrenoreceptor antagonists metipranolol and timolol are retinal neuroprotectants:comparision with betaxolol. Exp Eye Res. 2003 76;505-516

[52] Osborne NN, Wood JP, Chidlow G, Casson R, DeSantis L, Schmidt KG. Effectiveness of levobetaxolol and timolol at blunting retinal ischemia is related to their calcium and sodium blocking activities: relevance to glaucoma. Brain Res Bull 2004.62:525-528

[53] Gross RL, Hensley SH, Wu S. Retinal Ganglion Cell Dysfunction Induced by Hypoxia and glutamate: Potential Neuroprotective Effects of beta blockers. Surv Ophthalmol 1999; 43[Suppl 1]: S162-S170 
[54] Kaiser JH, Flammer J, Scumfig D, Hendrickson P, Long term follow up of glaucoma patients treated with beta blockers. Surv Ophthalmol 1994: 38 (Suppl):S156-S160

[55] Yu DY, Su EN, Cringle SJ, Alder VA, Yu PK, Desantis L.Effect of betaxolol, timolol and nimodipine on human and pig retinal arterioles.Exp Eye Res. 1998 ;67:73-81.

[56] Wood JP, De Santis L, Chao HM, Osborne NN. Topically applied betaxolol attenuates ischemia induced effects to the rat retina and stimulates BDNF mRNA Exp Eye Res. $2001: 72$;79-86

[57] Cheon EW, Park CH, Kang SS, et al. Betaxolol attenuates retinal ischemia/reperfusion damage in the rat. Neuroreport 2003; 14:1913-1917

[58] Shih GC, Calkins DJ Secondary neuroprotective effects of hypotensive drugs and potential mechanisms of action. Expert Rev. Ophthalmol 2012:7:161-175

[59] Yamagishi R, Aihara M, Araie M. Neuroprotective effects of prostaglandin analogues on retinal ganglion cell death independent of intraocular pressure reduction. Exp Eye Res. 2011;93:265-70

[60] Kniep EM, Roehlecke C, Ozkucur N, Steinberg A, Reber F, Knels L, Funk RH. Inhibition of apoptosis and reduction of intracellular $\mathrm{pH}$ decrease in retinal neural cell cultures by a blocker of carbonic anhydrase. Invest Ophthalmol Vis Sci. 2006;47:1185-92

[61] Tezel G. Oxidative stress in glaucomatous neurodegeneration: mechanisms and consequences. Prog Retin Eye Res.2006;25:490-513

[62] Pai-Huei P, Ho-Shiang H, Yih-Jing L, Yih-Sharng C, Ming-Chieh M Novel role for the $\delta$-opioid receptor in hypoxic preconditioning in rat retinas. Journal of Neurochemistry 2009; 108; 741-754

[63] Lam TT, Takahashi K, Tso MO. The effects of naloxone on retinal ischemia in rats.J Ocul Pharmacol. 1994;10:481-92.

[64] Riazi-Esfahani M., Kiumehr S., Asadi-Amoli F. et al. Morphine pretreatment provides histologic protection against ischemia-reperfusion injury in rabbit retina. Retina 2008; 28: 511-517

[65] Nakajima Y, Inokuchi Y, Nishi M, Shimazawa M, Otsubo K, Hara H. Coenzyme Q10 protects retinal cells against oxidative stress in vitro and in vivo. Brain Res. 2008 21;1226:226-33

[66] Nucci C, Tartaglione R, Cerulli A, Mancino R, Spanò A, Cavaliere F, Rombolà L, Bagetta G, Corasaniti MT, Morrone LA. Retinal damage caused by high intraocular pressure-induced transient ischemia is prevented by coenzyme Q10 in rat. Int Rev Neurobiol. 2007;82:397-406

[67] Osborne NN. Pathogenesis of ganglion "cell death" in glaucoma and neuroprotection: focus on ganglion cell axonal mitochondria. Prog Brain Res. 2008;173:339-52 
[68] Hirooka K, Tokuda M, Miyamoto O, et al. The gingko biloba extract (EGB 761) provides a neuroprotective effect on retinal ganglion cells in a rat model of chronic glaucoma. Cur Eye Res 2004;28:153-7

[69] Marcocci L, Parker L, Dry-Lefaix MT, et al. Anti-oxidant action of gingko bilboa extract (EGB) 761. Methods Enzymol 1994;234:462-75

[70] Quaranta L, Bettelli S, Uva MG, et al. Effect of gingko bilboa extract on preexisting visual field damage in normal tension pressure. Ophthalmology 2003;110:352-62

[71] Mey J, Thanos S. Intravitreal injections of neurotrophic factors support the survival of axotomized retinal ganglion cells in adult rats in vivo. Brain Res. 1993;602:304-17

[72] Ghaffariyeh A, Honarpisheh N, Heidari MH, Puyan S, Abasov F. Brain-derived neurotrophic factor as a biomarker in primary open-angle glaucoma Optom Vis Sci. $2011 ; 8: 80-5$

[73] Levin LA. Neuroprotection and regeneration in glaucoma Ophthalmol Clin North Am. 2005;18:585-96

[74] Pease ME, Zack DJ, Berlinicke C, Bloom K, Cone F, Wang Y, Klein RL, Hauswirth WW, Quigley HA. Effect of CNTF on retinal ganglion cell survival in experimental glaucoma. Invest Ophthalmol Vis Sci. 2009 May; 50: 2194-2200

[75] Agarwal R, Agarwal P. Glaucomatous neurodegeneration: An eye on tumor necrosis factor-alpha. Indian J Ophthalmol 2012;60:255-61

[76] Gabbita SP, Srivastava MK, Eslami P, Johnson MF, Kobritz NK, Tweed D, Greig NH, Zemlan FP, Sharma SP, Harris-White ME. Early intervention with a small molecule inhibitor for tumor necrosis factor- $\alpha$ prevents cognitive deficits in a triple transgenic mouse model of Alzheimer's disease. J Neuroinflammation. 2012;25:99. doi: 10.1186/1742-2094-9-99

[77] Roh M, Zhang Y, Murakami Y, Thanos A, Lee SC, Vavvas DG, Benowitz LI, Miller JW.Etanercept, a Widely Used Inhibitor of Tumor Necrosis Factor- $\alpha$ (TNF- $\alpha$ ), Prevents Retinal Ganglion Cell Loss in a Rat Model of Glaucoma. 2012;7:e40065. Epub 2012 Jul 3. (last access August 6th 2012)

[78] McKinnon SJ. The Cell and Molecular Biology of Glaucoma: Common Neurodegenerative Pathways and Relevance to Glaucoma. Invest. Ophthalmol. Vis. Sci.2012; $53: 2485-2487$

[79] Tezel G. TNF-alpha signaling in glaucomatous neurodegeneration Prog Brain Res. 2008;173:409-21

[80] Hong S, Kim CY, Lee WS, Shim J, Yeom HY, Seong GJ. Ocular hypotensive effects of topically administered agmatine in a chronic ocular hypertensive rat model. Exp Eye Res. 2010 ;90(1):97-103

[81] García E, Silva-García R, Mestre H, Flores N, Martiñón S, Calderón-Aranda ES, Ibarra A. Immunization with A91 peptide or copolymer-1 reduces the production of ni- 
tric oxide and inducible nitric oxide synthase gene expression after spinal cord injury. J Neurosci Res. 2012;90:656-63. doi: 10.1002/jnr.22771

[82] Schori H, Kipnis J, Yoles E, WoldeMussie E, Ruiz G, Wheeler L.A and Schwartz M. Vaccination for protection of retinal ganglion cells against death from glutamate cytotoxicity and ocular hypertension: Implications for glaucoma Proc Natl Acad Sci U S A. 2001; 98: 3398-3403

[83] Nilforushan N. Neuroprotection in glaucoma.J Ophthalmic Vis Res. 2012;7:91-3

[84] Husain S, Potter DE, Crosson CE. Opioid receptor-activation: retina protected from ischemic injury. Invest Ophthalmol Vis Sci. 2009;50:3853-9

[85] Husain S, Abdul Y, Potter DE. Non-Analgesic Effects of Opioids: Neuroprotection in the Retina Curr Pharm Des. 2012 Jun 28. [Epub ahead of print] http:// www.ncbi.nlm.nih.gov/pubmed/22747547 (last access August 5th 2012)

[86] Bull ND, Irvine KA, Franklin RJ, Martin KR. Transplanted oligodendrocyte precursor cells reduce neurodegeneration in a model of glaucoma. Invest Ophthalmol Vis Sci. 2009;50:4244-4253

[87] Tatton WG.Apoptotic mechanisms in neurodegeneration: possible relevance to glaucoma. Eur J Ophthalmol. 1999 Jan-Mar;9 Suppl 1:S22-9

[88] Qi X, Sun I, Lewin AS, et al. Long term suppression of neurodegeneration in chronic experimental optic neuritis:anti-oxidant gene therapy. Invest Ophthalmol Vis Sci 2007;48:5360-70

[89] Borrás T.Advances in glaucoma treatment and management: gene therapy. Invest Ophthalmol Vis Sci. 2012 4;53:2506-10.

[90] Di Polo A, Aigner LJ, Dunn RJ, et al. Prolonged delivery of brain derived neurotrophic factor by adenovirus infected Muller cells temporarily rescues injured retinal ganglion cells. Pro Natl Acad Sci USA. 1998;95:3978-83 